\title{
Dispersion Compensation Requirements for Optical CDMA Using WDM Lasers
}

A. J. Mendez, V. J. Hernandez, H. X. C. Feng, J. P. Heritage, W. J. Lennon

This article was submitted to Photonics West, San Jose, CA, January 19-25, 2002

\section{December 10, 2001}

U.S. Department of Energy

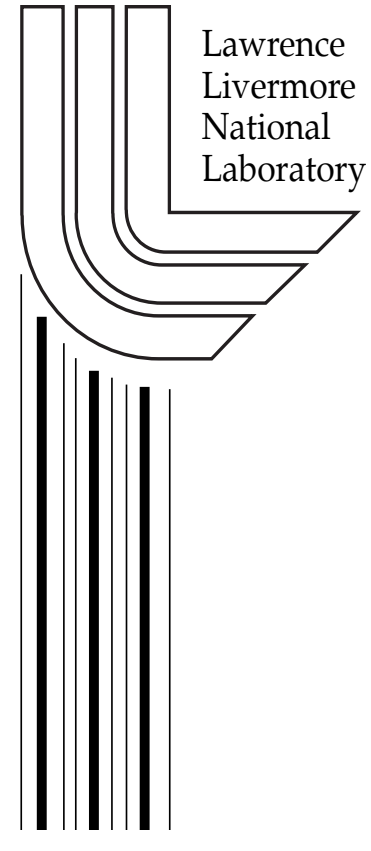




\section{DISCLAIMER}

This document was prepared as an account of work sponsored by an agency of the United States Government. Neither the United States Government nor the University of California nor any of their employees, makes any warranty, express or implied, or assumes any legal liability or responsibility for the accuracy, completeness, or usefulness of any information, apparatus, product, or process disclosed, or represents that its use would not infringe privately owned rights. Reference herein to any specific commercial product, process, or service by trade name, trademark, manufacturer, or otherwise, does not necessarily constitute or imply its endorsement, recommendation, or favoring by the United States Government or the University of California. The views and opinions of authors expressed herein do not necessarily state or reflect those of the United States Government or the University of California, and shall not be used for advertising or product endorsement purposes.

This is a preprint of a paper intended for publication in a journal or proceedings. Since changes may be made before publication, this preprint is made available with the understanding that it will not be cited or reproduced without the permission of the author.

This work was performed under the auspices of the United States Department of Energy by the University of California, Lawrence Livermore National Laboratory under contract No. W-7405-Eng-48.

This report has been reproduced directly from the best available copy.

Available electronically at http://www.doc.gov/bridge

Available for a processing fee to U.S. Department of Energy

And its contractors in paper from

U.S. Department of Energy

Office of Scientific and Technical Information

P.O. Box 62

Oak Ridge, TN 37831-0062

Telephone: (865) 576-8401

Facsimile: (865) 576-5728

E-mail: reports@adonis.osti.gov

Available for the sale to the public from

U.S. Department of Commerce

National Technical Information Service

5285 Port Royal Road

Springfield, VA 22161

Telephone: (800) 553-6847

Facsimile: (703) 605-6900

E-mail: orders@ntis.fedworld.gov

Online ordering: http://www.ntis.gov/ordering.htm

OR

Lawrence Livermore National Laboratory

Technical Information Department's Digital Library

http://www.llnl.gov/tid/Library.html 


\title{
Dispersion Compensation Requirements for Optical CDMA Using WDM Lasers
}

\author{
Antonio J. Mendez ${ }^{a}$; Vincent J. Hernandez ${ }^{b}$; Helena X. C. Feng ${ }^{c}$; Jonathan P. Heritage ${ }^{d}$; \\ and William J. Lennon ${ }^{b}$ \\ ${ }^{a}$ Mendez R\&D Associates (MRDA) ; P.O. Box 2756, El Segundo, CA 90245; \\ ${ }^{b}$ Lawrence Livermore National Laboratory (LLNL) ; P.O. Box 808, L-541, Livermore, CA 94551; \\ ${ }^{c}$ University of California/Davis, Department of Applied Science, Davis, CA 95616; \\ ${ }^{d}$ University of California/Davis, ENG 2, Davis, CA 95616
}

\begin{abstract}
Optical code division multiple access (O-CDMA) uses very narrow transmission pulses and is thus susceptible to fiber optic link impairments. When the O-CDMA is implemented as wavelength/time (W/T) matrices which use wavelength division multiplexing (WDM) sources such as multi-frequency laser transmitters, the susceptibility may be higher due to: (a) the large bandwidth utilized and (b) the requirement that the various wavelength components of the codes be synchronized at the point of modulation and encoding as well as after (optical) correlation. A computer simulation based on the nonlinear Schrödinger equation, developed to study optical networking on the National Transparent Optical Network (NTON), was modified to characterize the impairments on the propagation and decoding of W/T matrix codes over a link of the NTON. Three critical link impairments were identified by the simulation: group velocity dispersion (GVD); the flatness of the optical amplifier gain; and the slope of the GVD. Subsequently, experiments were carried out on the NTON link to verify and refine the simulations as well as to suggest improvements in the W/T matrix signal processing design. The NTON link measurements quantified the O-CDMA dispersion compensation requirements. Dispersion compensation management is essential to assure the performance of $\mathbf{W} / \mathbf{T}$ matrix codes.
\end{abstract}

Keywords: Dispersion compensation; Optical CDMA; WDM; Optical fiber

\section{INTRODUCTION}

O-CDMA uses narrow transmission pulses (because it needs return-to-zero, RZ, modulation with less than 25\% duty cycle $^{1-7}$ ). Hence O-CDMA is susceptible to link impairments, especially as the data rate exceeds one $\mathrm{Gb} / \mathrm{s}$. If the $\mathrm{O}$ CDMA is based on matrix codes implemented as W/T matrices ${ }^{6,8,9}$ which use WDM sources such as multi-frequency laser transmitters, MFLs ${ }^{10,11}$, then the susceptibility may be higher than that of monochromatic O-CDMA because of the bandwidth utilized (e.g., number of wavelengths in the code set times the $100 \mathrm{or} 200 \mathrm{GHz}$ spacing of the MFLs) and (b) the strict requirement that the various signal wavelengths in the codes be synchronized at the point of modulation (data insertion and encoding) as well as after transmission and (optical) correlation.

Despite these potential sensitivities to link impairments, the W/T matrix approach has the benefits and advantages that

(1) the matrix codes are an order of magnitude less demanding than linear codes with respect to the time domain;

(2) the W/T matrix codes act as a WDM wavelength multiplier; and (3) the W/T matrix codes have a spectral efficiency (bit/s/Hz) comparable to $\mathrm{WDM}^{6}$.

Hence it is crucial to identify the link impairments on the propagation of O-CDMA codes, and to define the corresponding compensation requirements. Towards this objective, a computer simulation based on the nonlinear Schrödinger equation, using a split-step technique (developed to study optical networking on the NTON) was modified and applied to a link of the NTON to characterize specifically the impairments on the propagation and decoding of W/T matrices ${ }^{12,13}$.

The simulation identified three critical link impairments which affect the propagation and performance of W/T matrices: (1) the group velocity dispersion (GVD); (2) the flatness of the optical amplifier gain; and (3) the slope of the GVD. 
The simulation also computed that four-wave-mixing (FWM) would be an observable feature in the spectra of the propagated W/T matrices, and that the field, rather than the intensity, was the proper descriptor for modeling and analyzing the O-CDMA performance. (The later observation is important because, like most O-CDMA codes, the W/T codes are unipolar and most O-CDMA signal-to-interference ratio analyses are based on the intensities of the signal and multi-user interference, MAI. The issue of the field vs the intensity picture will be discussed in detail elsewhere.)

Therefore, experiments were designed to verify the simulation results. The measurements carried out on the NTON link quantify the three primary link impairments and show that amplified spontaneous emission noise masks the FWM.

\section{DESCRIPTION OF THE NTON LINK, EXPERIMENTS, AND TEST SET-UP}

Figure 1 shows the specific NTON link used for the code propagation experiments. The link was used in a back -to-back configuration and then in a loop-back configuration, to simplify the experiment's coordination. The back-to-back (laboratory) configuration defines the impairment-free condition, and the loop-back configuration includes all impairments: the GVD, attenuation, EDFA gain imbalance, nonlinearities, etc.

The simulation modeled the propagation of the W/T matrix codes from Lawrence Livermore National Laboratory (LLNL) to Burlingame (Sprint facility), whereas the code propagation measurements involve a round trip (LLNL>Burlingame->LLNL), by means of a loop-back patch at Burlingame, as mentioned above. Thus, the simulated link is $214 \mathrm{~km}$, and the measured link is $476 \mathrm{~km}$. Both the simulation and the measurements include Standard single mode fiber (SMF-28) and Corning LEAF, in about a 3:1 ratio in length. The measurements should show more pronounced effects than the simulation. The corning LEAF is more optimized for operation in the $1550 \mathrm{~nm}$ regime compared to the SMF-28.

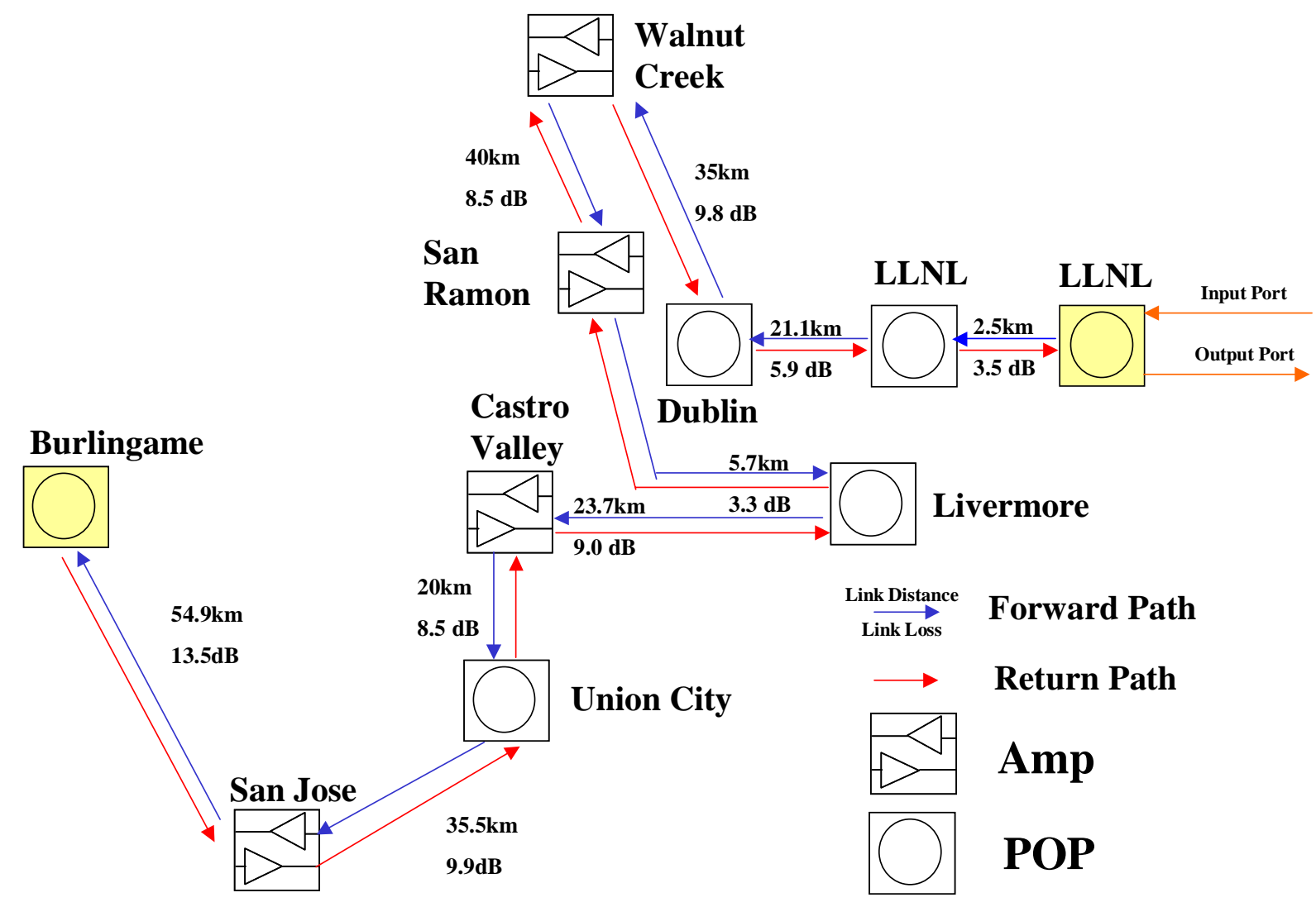

Figure 1. Description of the NTON Link Used in the Validation/Evaluation Experiments. 
Figure 2 shows the details of the laboratory and field experimental arrangement. Key subassemblies are: the MultiFrequency Laser (MFL) module ${ }^{8,10,11}$ granted to MRDA by its developer, the Lucent Technologies/Bell Labs, for exploring O-CDMA applications; the external RZ modulator which permits the synchronous, simultaneous modulation of multiple wavelengths; the $3 \mathrm{GHz}$ signal generator; the broadband receiver and oscilloscope which can detect and record the W/T pulse stream in the back-to-back and loop-back configurations; and the spectrum analyzer which can measure and depict the optical signal-to-noise ratio before and after traversal of the NTON link.

Not shown in the figure are the various dispersion compensation modules (DCMs) which can be inserted to correct, at least in part, the effects of GVD.

Detecting and recording the W/T pulse stream in the loop-back configuration can be used to deduce the GVD relative to the shortest wavelength in the W/T set. Recording the output of the spectrum analyzer in the loop-back configuration can be used to measure the EDFA gain imbalance and determine if FWM is observable.

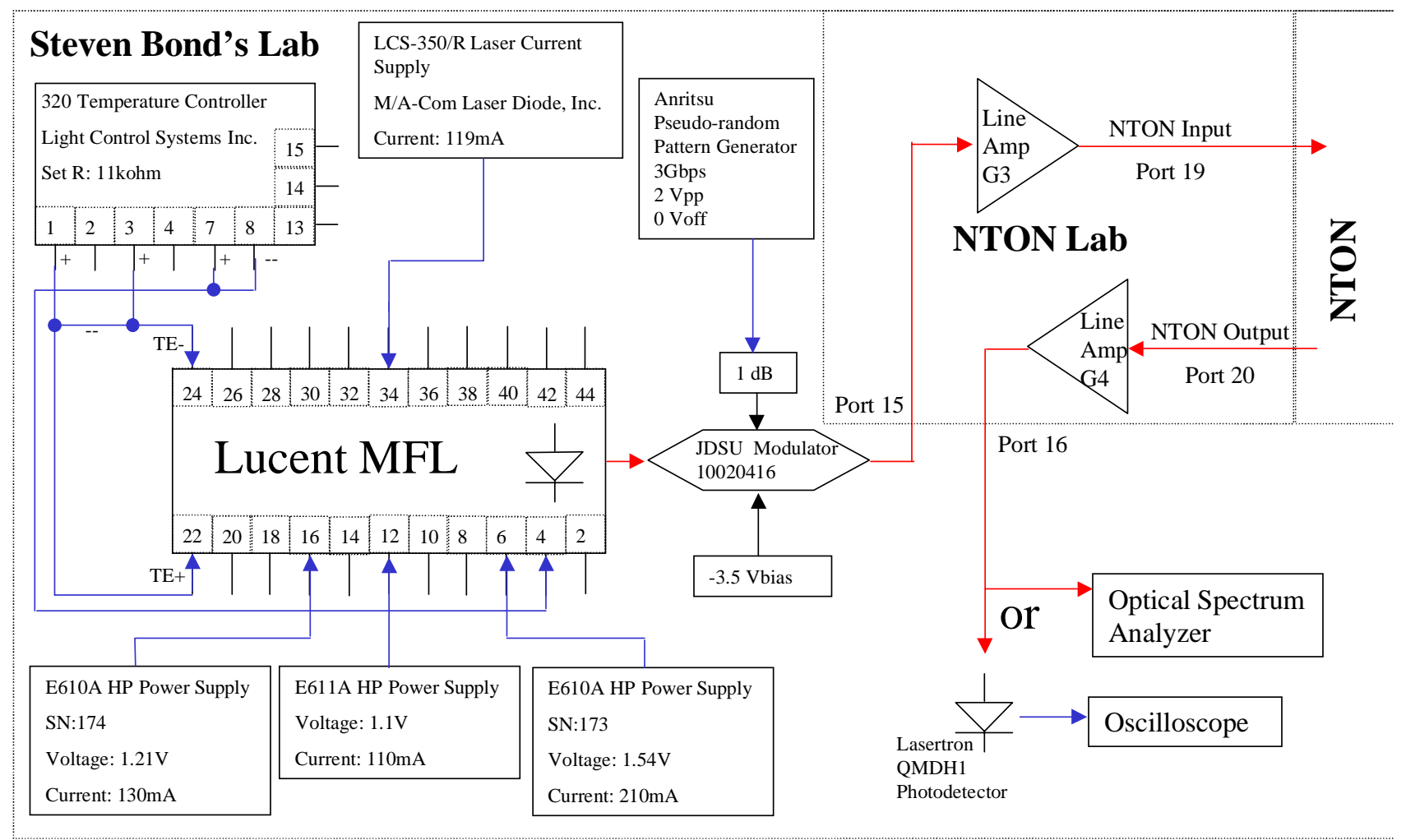

RF Connection

Fiber Connection

Figure 2. The LLNL NTON Transmit/Receive Laboratory Configuration.

The tests and experiments performed by LLNL included:

\section{TESTS AND EXPERIMENTS CARRIED OUT}

(1) sending and recording the signal and the spectrum of a single wavelength and a quartet of wavelengths in a back-to-back configuration (the quartet simulates the W/T matrix codes);

(2) sending and recording the signal and the spectrum of a single wavelength and a quartet of wavelengths in a loop-back configuration.

The set of experiments included in (1) establishes the reference for calibration purposes. The set of experiments included 
in (2) determines the effects of the link impairments on code propagation. The results of experiment set (2) can also be used to define the dispersion compensation strategy, to determine whether FWM is observable, and to referee the intensity vs field picture. (As mentioned Section 1, the issue of the field vs intensity picture will be treated elsewhere.)

Figure 3a shows the output of the MFL/LiNbO 3 modulator combination, operated at the maximum bandwidth of the signal generator $(3 \mathrm{GHz})$. All wavelengths of the MFL are included, and they all have the trapezoidal pulse shape. Figure $3 \mathrm{~b}$ shows the pulse shape at a given wavelength, after loop-back (the wavelengths have been spaced out by the effects of dispersion). The trapezoidal pulse has been broadened and transformed into a triangular pulse. This effect was seen for all wavelengths.

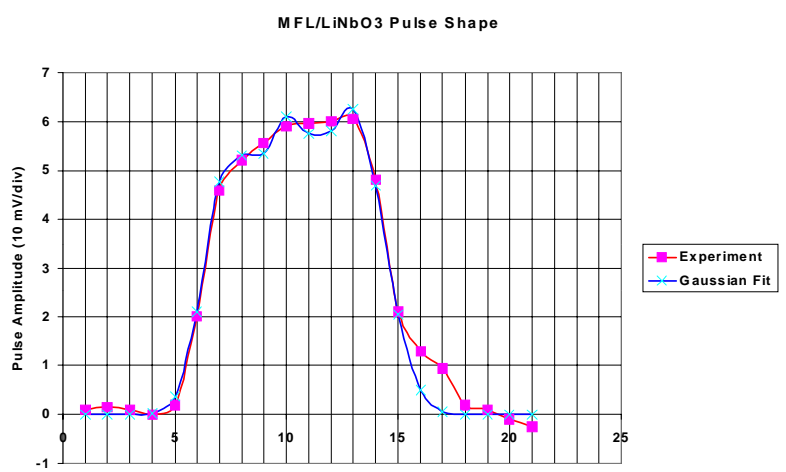

Time (40 ps/div)

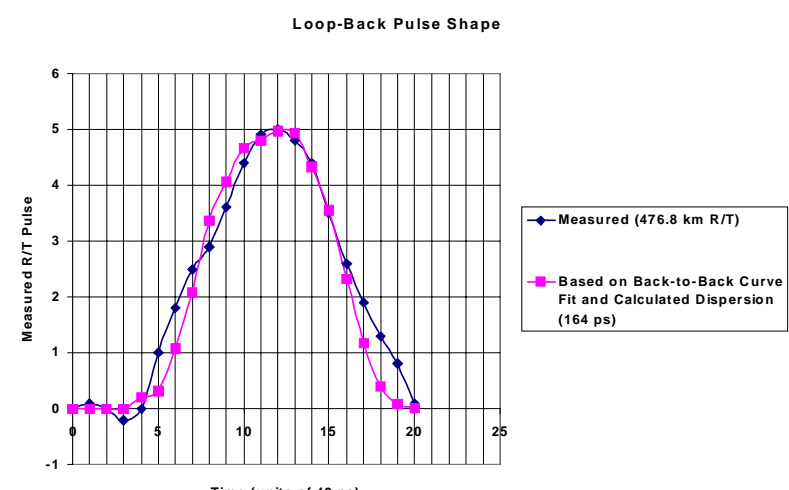

Time (units of $40 \mathrm{ps}$ )

(a)

(b)

Figure 3. Pulse Shape at Output of MFL/Modulator (a) and After Loop-Back (b).

The effects of GVD and EDFA gain imbalance were measured by launching the quartet of pulses with wavelengths $\lambda 1, \lambda 3, \lambda 5, \lambda 8$ and capturing the signal after loop-back. Typical results are shown in Figure 4 . The quartet has been spread-out in time (the scale is $5 \mathrm{~ns} / \mathrm{div}$ ) and the pulse amplitudes are unequal.

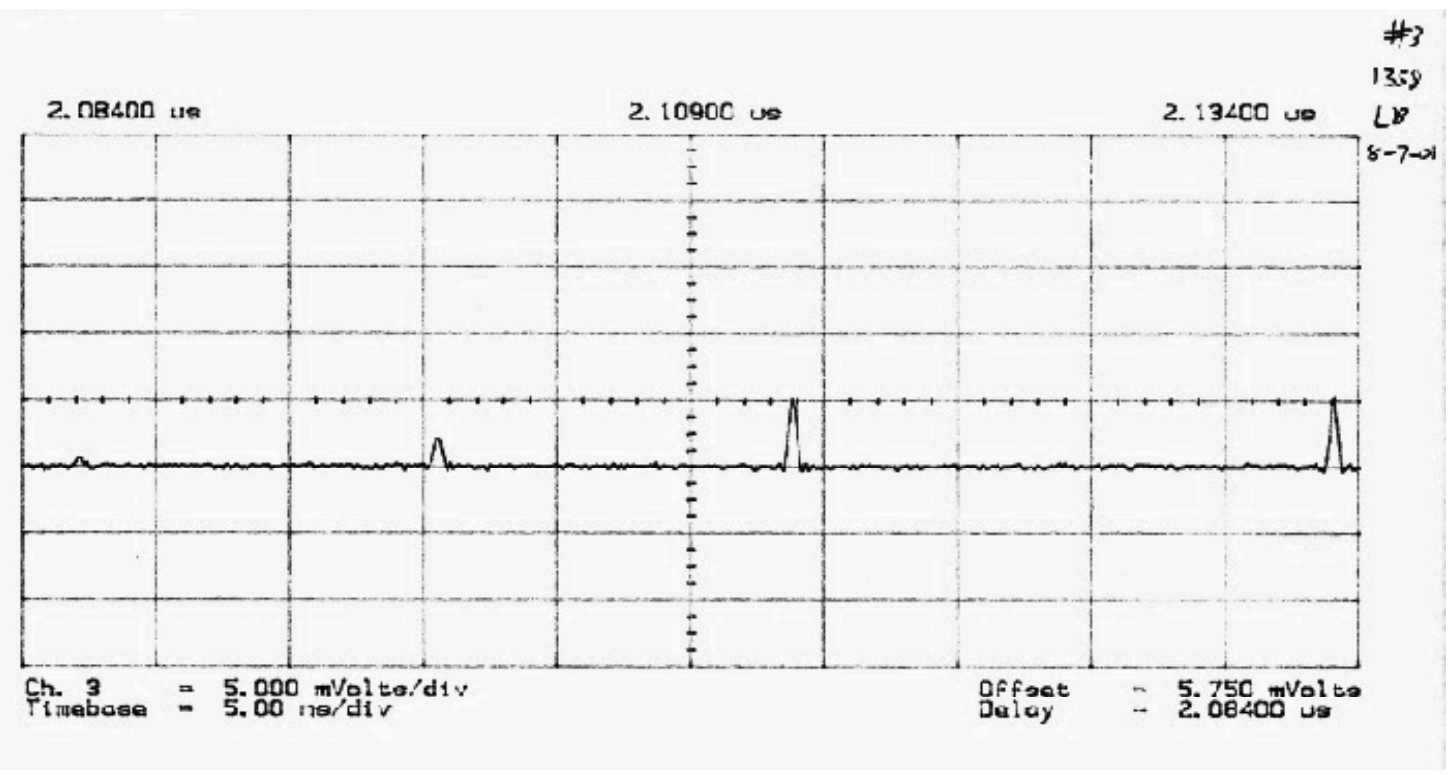

Figure 4. Effects of GVD and EDFA Gain Imbalance on the Quartet $\lambda 1, \lambda 3, \lambda 5, \lambda 8$. 
Figure 5 shows the spectra of the quartet at the output of the MFL/modulator and after loop-back. The spectra clearly show the effect of EDFA gain imbalance; the presence and magnitude of ASE noise; and the absence of observable FWM. The FWM is not evident in Figure $5 b$, in contrast to the expectations of simulation results ${ }^{12}$, because it is masked by the much larger ASE power (analytical computations indicate that the ASE exceeds the FWM power by $6 \mathrm{~dB}$ ). The loop-back spectrum shows an optical signal-to-noise ratio (OSNR) of 23 to $28 \mathrm{~dB}$, from $\lambda 1$ to $\lambda 8$.

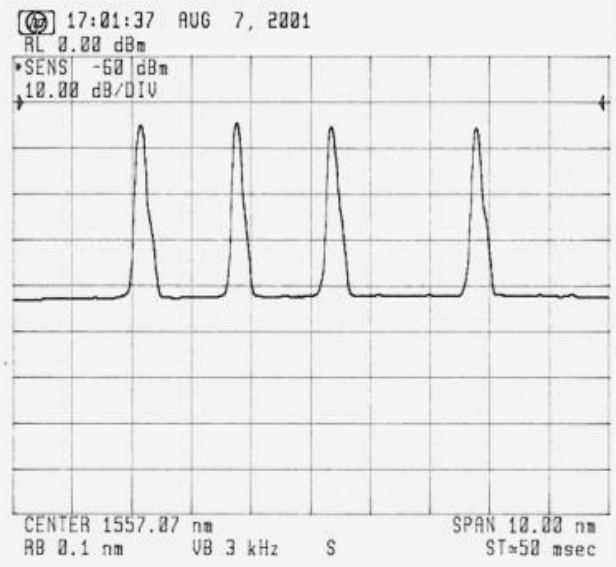

(a)

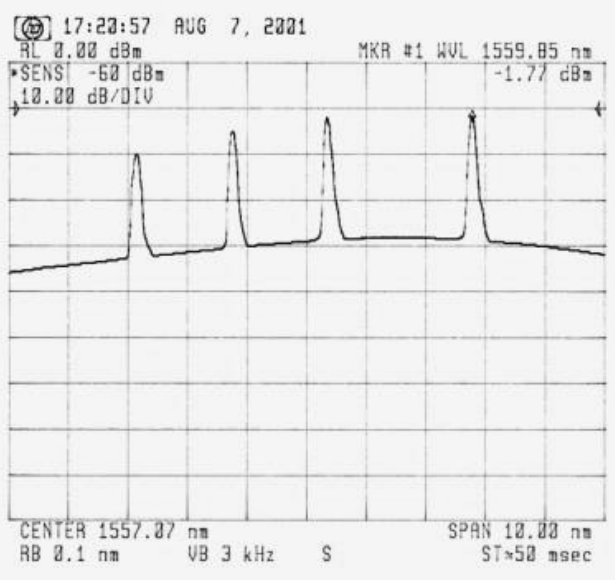

(b)

Figure 5. Output (a) and Loop-Back (b) Spectra of the Quartet.

\section{ANALYSIS OF THE DISPERSION TEST RESULTS}

The results of the time-trace of the dispersion effects, Figure 4, can be represented as dispersion relative to the shortest wavelength (i.e., relative dispersion; the dispersion compensation need only relate to the shortest wavelength if the dispersion is positive). Figure 6 shows the actual dispersion (in ps) from shortest to longest wavelength; i.e., $\lambda 1$ to $\lambda 8$.

Figure 6 also shows the residual dispersion after the dominant dispersion is compensated by a linear compensation mechanism. The figure shows that the $\lambda 1-\lambda 8$ dispersion, over this $476 \mathrm{~km}$ link, is about 47,000 ps (47 ns).

The dispersion curvature effect, which would lead to skew ${ }^{12}$ if the linear effect were compensated, is of the order of 500 ps at some of the code wavelengths (right vertical axis). Since the codes use the available wavelengths in a more or less random fashion, the effect of linear dispersion and dispersion curvature is more severe for some codes than others. In all cases, the components of the autocorrelation peak must be aligned to within 1 to $2.5 \%$ of $1 / \mathrm{R}$, where $\mathrm{R}=$ data rate ${ }^{14}$.

The experimental results can be understood in terms of the dispersion characteristics of the NTON loop-back link. The manufacturer (Corning) gives the fiber dispersion characteristics for SMF-28 and LEAF as

$$
\begin{aligned}
\mathrm{D} 1(\mathrm{SMF}-28) & =0.023\left(\lambda-\left((1312)^{\wedge} 4\right) /(\lambda)^{\wedge} 3\right) \mathrm{ps} / \mathrm{nm}-\mathrm{km} \\
\mathrm{D} 2(\mathrm{LEAF}) & =0.1 * \lambda-151.3 \mathrm{ps} / \mathrm{nm}-\mathrm{km}
\end{aligned}
$$

with the length of the SMF portion being L1 $(\mathrm{SMF}-28)=179.8 \mathrm{~km}$; the length of the LEAF portion being L2 $(\mathrm{LEAF})=$ $58.6 \mathrm{~km}$; and the reference wavelength being $\lambda=1555 \mathrm{~nm}$. Then the Net Loop-Back Dispersion is

$$
\begin{aligned}
2 * \mathrm{D}(\mathrm{L} 1+\mathrm{L} 2) & =2 *(\mathrm{D} 1 * \mathrm{~L} 1+\mathrm{D} 2 * \mathrm{~L} 2) \\
& =6836 \mathrm{ps} / \mathrm{nm}
\end{aligned}
$$


Given a $3 \mathrm{GHz}$ modulation bandwidth, the computed broadening of the loop-back pulse is $164 \mathrm{ps}$, and this is consistent with the pulse broadening observed in Figure 3.

\section{Relative Delay Due to Dispersion}

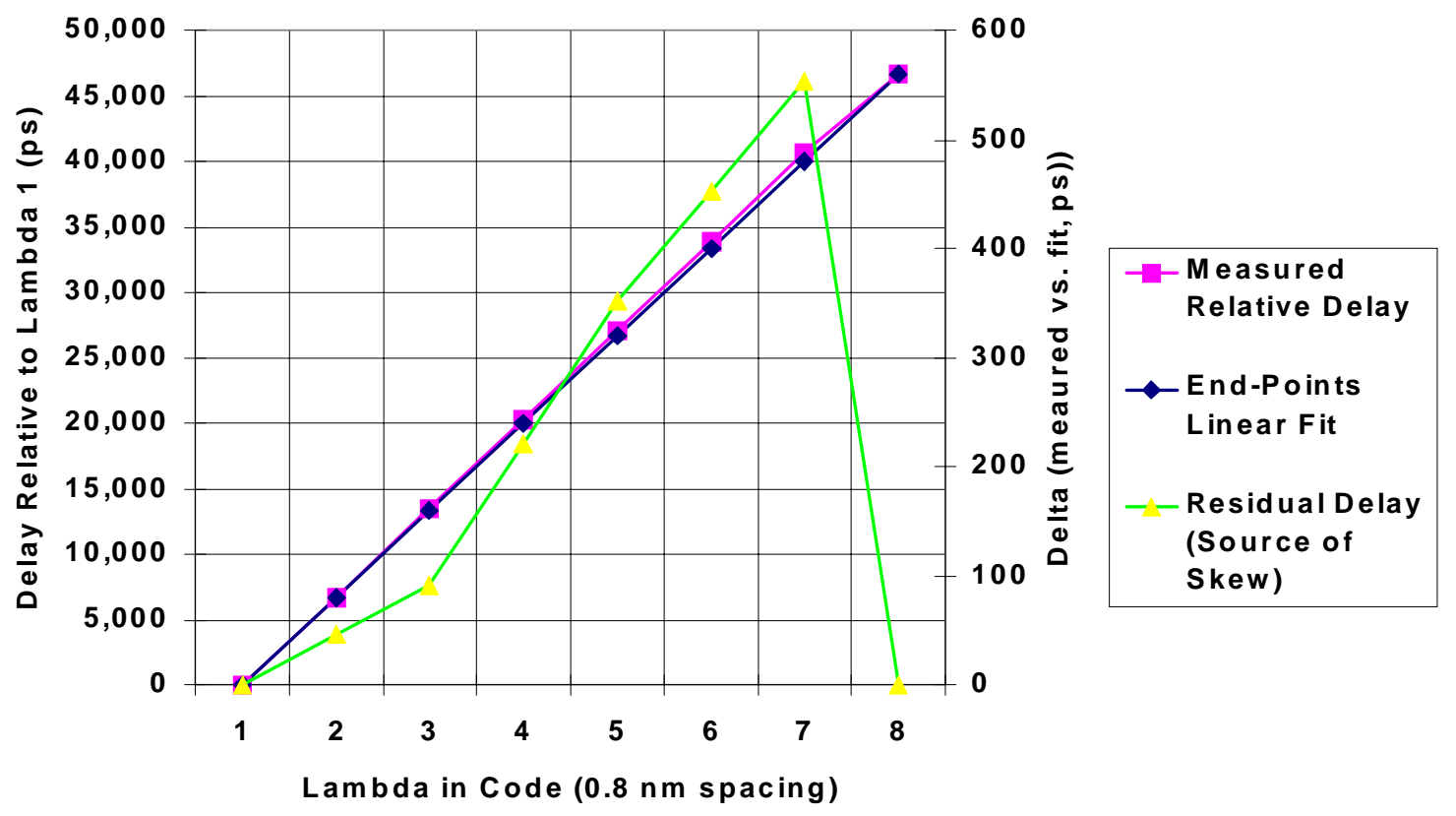

Figure 6. Measured Dispersion and Dispersion Curvature Over the NTON Link.

Using the MFL wavelength spacing of $100 \mathrm{GHz}$, Eqn. (3) gives 38,282 ps for the expected dispersion between $\lambda 1$ and $\lambda 8$, compared to the 47,000 actually observed. Thus, the effective dispersion associated with the various fibers must be improved in order for the simulation and experiments to match. In any case, the probe measurements described above are exact and take precedence over the analysis in specifying the dispersion compensation requirements.

\section{CONCLUDING REMARKS}

A new, powerful approach to O-CDMA is based on W/T matrix codes. These codes act as wavelength multipliers and support multiple, asynchronous, concurrent user-pairs. Simulations have been used to evaluate the propagation of these codes over installed fiber optic links such as the NTON. The simulations have shown that the GVD, EDFA gain flatness, and GVD slope are critical impairments of O-CDMA (especially W/T matrix code) system performance. Thus, the simulations predict that strict GVD compensation and EDFA gain flatness control are required. Experiments performed over an NTON link support and validate these simulation results.

\section{ACKNOWLEDGEMENTS}

MRDA's work was supported in part by U.S. Department of Energy Grant ER83277. MRDA is grateful to the Lucent Technologies/Bell Labs for their generous grant of the $100 \mathrm{GHz}$ MFL. The authors particularly acknowledge NTON members Nortel Networks, Sprint, and LLNL for their support. The NTON is sponsored in part by the Department of Defense Advanced Research Projects Agency (DARPA) and the NTON Consortium. The authors would like to thank Stephen W. Bond of LLNL for his generous loan of his NTON laboratory facilities and equipment, and Brian Bodtker for his NTON support at LLNL. This work was performed under the auspices of the U.S. Department of Energy by the University of California, Lawrence Livermore National Laboratory, under Contract No. W-7405-Eng-48. 


\section{REFERENCES}

1. $\quad$ Paul E. Green, Jr.; Fiber Optic Networks; Prentice Hall, Englewood Cliffs, NJ; 1993.

2. P.R. Prucnal, M.A. Santoro, and T.R. Fan, "Spread spectrum fiber-optic local area network using optical processing", IEEE J. Lightwave Technol., vol. LT-4, p. 547 (1986).

3. F. Khansefid, H. Taylor, and R. Gagliardi, "Design of $(0,1)$ Sequence Sets For Pulsed Coded Systems", University of Southern California Report CSI-88-03-03, March 3, 1988.

4. A. J. Mendez, J. L. Lambert, J.-M. Morookian, and R. M. Gagliardi, "Synthesis and Demonstration of High Speed, Bandwidth Efficient Optical Code Division Multiple Access (CDMA) Tested at $1 \mathrm{~Gb} / \mathrm{s}$ Throughput", IEEE Photon. Technol. Lttr., Vol. 6, pp. 1146-1149 (1994).

5. T. Pfeiffer, B. Deppisch, M. Witte, and R. Heidemann, "Optical CDMA Transmission for Robust Realization of Complex and Flexible Multiple access Networks", OFC'99 Conf. Proc., paper WM51-1.

6. A. J. Mendez and R. M. Gagliardi, "Wavelength Multiplication and Capaci ty Enhancement of Optical Code Division Multiplexing (O-CDM) Based on Wavelength/Time (W/T) Matrix Codes”, IEEE/LEOS 2000 Annual Meeting, paper $\mathrm{ThO} 2$.

7. H. Ben Jaafar, S. LaRochelle, P.-Y. Cortes, and H. Fathallah, " $1.25 \mathrm{~Gb} / \mathrm{s}$ transmission of optical FFH-OCDMA over $80 \mathrm{~km}$ with 16 users", OFC 2001, OFC Technical Digest Series, paper TuV3, March 2001.

8. A. J. Mendez, "Application of Multifrequency Lasers (MFLs) to Optical CDMA", Proc. 10th DARPA Symposium on Photonic Systems for Antenna Applications (PSAA-10), February 17, 2000.

9. A. J. Mendez, R. M. Gagliardi, H. X. C. Feng, J. P. Heritage, and J.-M. Morookian, "Strategies for Realizing Optical CDMA for Dense, High Speed, Long Span, Optical Network Applications”, J. Lightwave Technol., Special Issue on Optical Networks, Vol. 18, pp. 1685-96 (2000).

10. M. Zirngibl, "Multifrequency Lasers and Applications in WDM Networks" IEEE Communications Magazine, December (1998).

11. C.R. Doerr, C.H. Joyner, and L.W. Stulz, "Multifrequency Laser with Reduced Intracavity Wave Mixing", Photon. Technol. Lttr., Vol.11, p. 635-637 (1999).

12. H. X. C. Feng, A. J. Mendez, J. P. Heritage, and W. J. Lennon, "Effects of Optical Layer Impairments on 2.5 Gb/s Optical CDMA Transmission", Optics Express, Vol. 7, pp. 2-9 (2000), http://epubs.osa.org/opticsexpress/topbiframe.htm.

13. H. X. C. Feng, L. R. Thombley, W. J. Lennon, J. P. Heritage, "Computer Modeling of the National Transparent Optical Network (NTON)", IEEE/LEOS'99 Annual Mtg, paper WP1. (Invited).

14. A. J. Mendez and J.-M. Morookian, "Return-to-Zero (RZ) Modulation of Multi-Frequency Lasers for Application to Optical CDMA", Photonics West'02, SPIE Vol. 4653, paper 14, to be published. 